\title{
Localized Nodular Tenosynovitis Originated near the Medial Plicae
}

\author{
Young-Mo Kim, MD and Yong Bum Joo, MD \\ Department of Orthopaedic Surgery, Chungnam National University Hospital, Daejeon, Korea
}

\begin{abstract}
The authors report a case of localized nodular tenosynovitis originating from the medial plicae of the knee that was grossly observable, palpable, and symptomatic. A 41-year-old male visited our hospital with a complaint of knee pain that began 4 years ago. He complained of intermittent catching and a mass that appeared in the medial side of the knee 18 months ago. On magnetic resonance imaging, the mass was found on the plicae area of the medial side of the knee, and thus excisional biopsy was performed under arthroscopy. Histological study showed characteristics of localized nodular tenosynovitis originating from the synovium of the knee. At the 1-year postoperative outpatient follow-up, no symptoms or signs of recurrence were found. Since the authors experienced excellent postoperative results of arthroscopically assisted resection of a grossly observable and palpable localized nodular tenosynovitis originating from the synovium of the knee plicae, we report the case with a review of the literature.
\end{abstract}

Keywords: Knee, Medial plicae, Nodular tenosynovitis

Giant cell tumor of tendon sheath is a relatively common disease that originates from the synovium, which can be divided into localized nodular tenosynovitis and diffuse pigmented villonodular synovitis. Localized nodular tenosynovitis usually occurs in the synovium of the metacarpophalangeal joint of the hand ${ }^{1-3)}$ and, though rare, once it occurs in the knee, it affects all portions of the synovium including the anterior and posterior cruciate ligaments $^{4-7)}$. In such a case, 1) the tenosynovitis is located in the synovium just above the medial plicae; 2) it is intermittently noted as a palpable mass on the skin and causes mechanical symptoms by compression of adjacent bony and soft tissue; and 3) even if not palpable, the mass in the patellofemoral joint evokes mechanical symptoms in the joint. The authors report a case of

Received October 10, 2012; Revised (1st) August 12, 2013;

(2nd) September 30, 2013; (3rd) October 8, 2013;

Accepted October 10, 2013

Correspondence to: Yong Bum Joo, MD

Department of Orthopaedic Surgery, Chungnam National University

Hospital, 282 Munhwa-ro, Jung-gu, Daejeon 301-721, Korea

Tel: +82-42-280-7340, Fax: +82-42-252-7098

E-mail: longman76@hanmail.net

This is an Open Access article distributed under the terms of the Creative Commons Attribution Non-Commercial License (http://creativecommons.org/licenses/by-nc/3.0/) which permits unrestricted non-commercial use, distribution, and reproduction in any medium, provided the original work is properly cited. localized nodular tenosynovitis that originated from the synovium just above the medial plicae of patella and caused mechanical symptoms with a review of the literature.

\section{Case Report}

A 41-year-old male was admitted to the hospital with a major complaint of left knee pain that began 3-4 years ago. There was no specific history of trauma or infection on the left knee. The patient reported intermittent knee pain and feeling of irritation (catching) during flexion and extension of the knee that had been present for 3-4 years. Due to persistent pain and irritating feeling upon squatting and over $100^{\circ}$ of flexion, activities involving knee flexion was impossible. Since 18 months ago, a mass was palpable on the skin in the medial side of the left knee, and it moved underneath the skin when pressed by the hand. When the mass was checked or palpated on the medial skin of the knee, the pain with locking worsened, whereas when it was not palpated after being pressed underneath the skin, the feature of the symptom was similar but the severity was relieved. On physical examination, a mass with the size of a bean was observed on the medial surface of the patella, and tenderness was present. Simple radiography did not demonstrate any shadow of mass or local bony erosion, and the joint space appeared normal.

On magnetic resonance imaging (MRI), the area where the www.jksrr.org 
medial plicae is present inferomedial to the patellofemoral joint showed equal intermediate-low signal intensity on $\mathrm{T} 1$ images and a $8 \times 11 \times 7 \mathrm{~mm}$ sized oval-shaped mass with a low signal intensity was found on T2 images (Fig. 1). On the contrast enhanced images, findings of specific enhancement and effusion of synovial fluid or synovitis were not present.
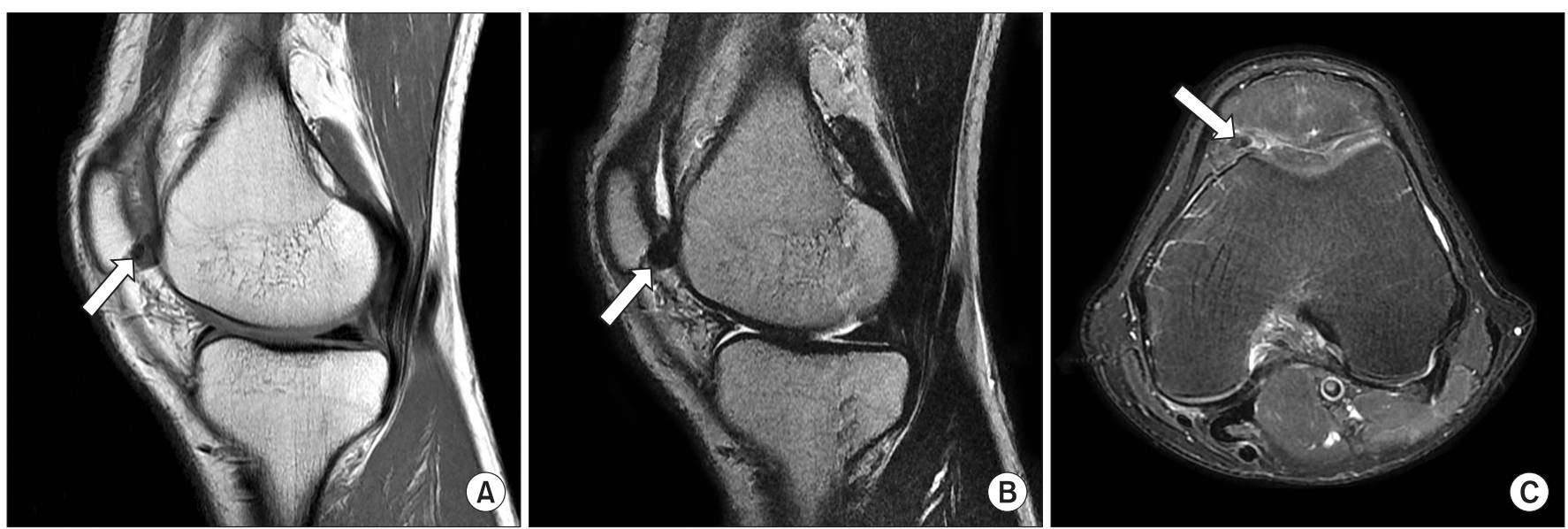

Fig. 1. Magnetic resonance imaging showed a mass in the inferomedial aspect of the patellofemoral joint. (A) On T1 image, a mass with homogenous intermediate signal intensity was seen in the patellofemoral joint. $(\mathrm{B}, \mathrm{C}) \mathrm{On} \mathrm{T} 2 \mathrm{images}$, a mass with homogenous low signal intensity was seen.
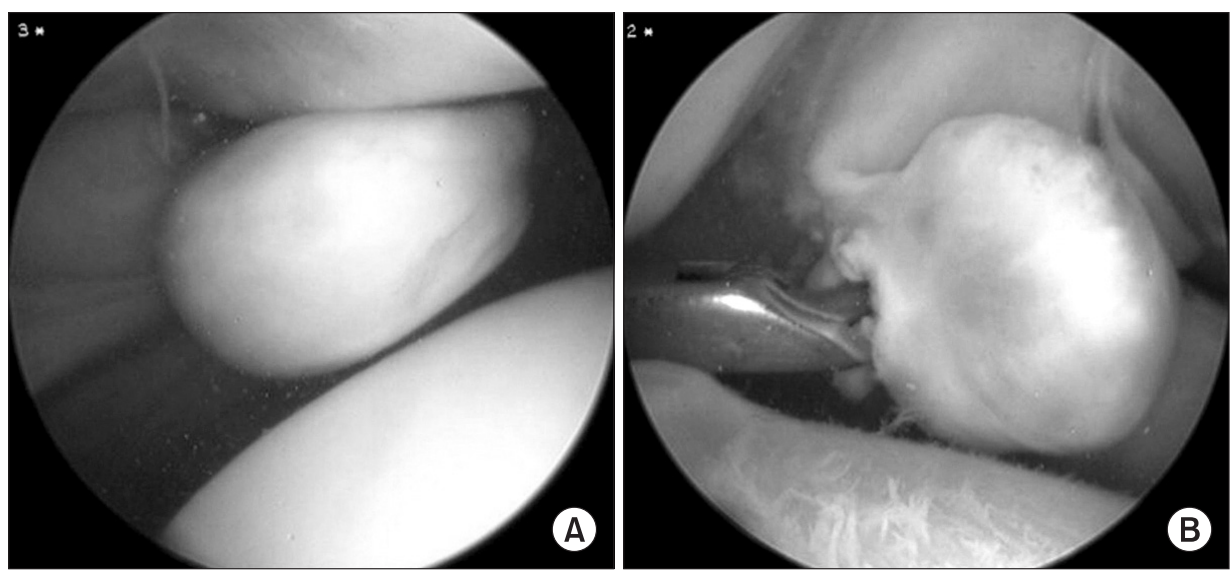

B
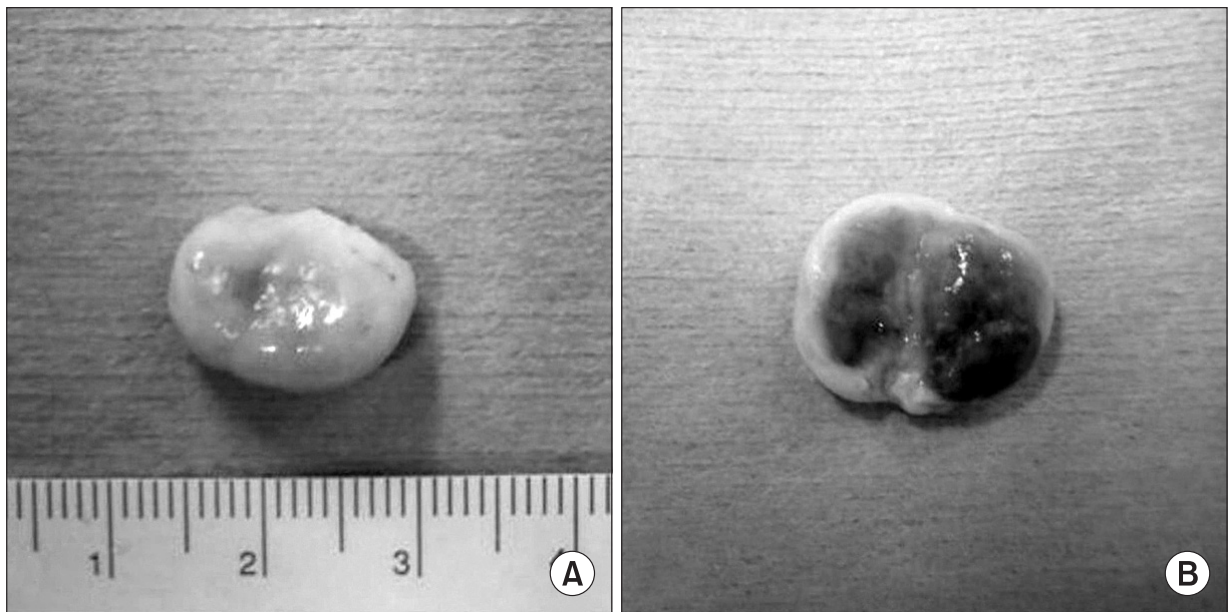

Fig. 3. (A, B) Gross examination of the mass showed white-yellow colored soft mass. The inner side of the mass showed dark-brown color.
Fig. 2. (A) On the anterolateral portal view, there was a soft tissue mass on the medial plicae as a pedunculated type. It was whitepinkish, ovoid, and soft. (B) The soft tissue mass was removed with an arthroscopic punch. 

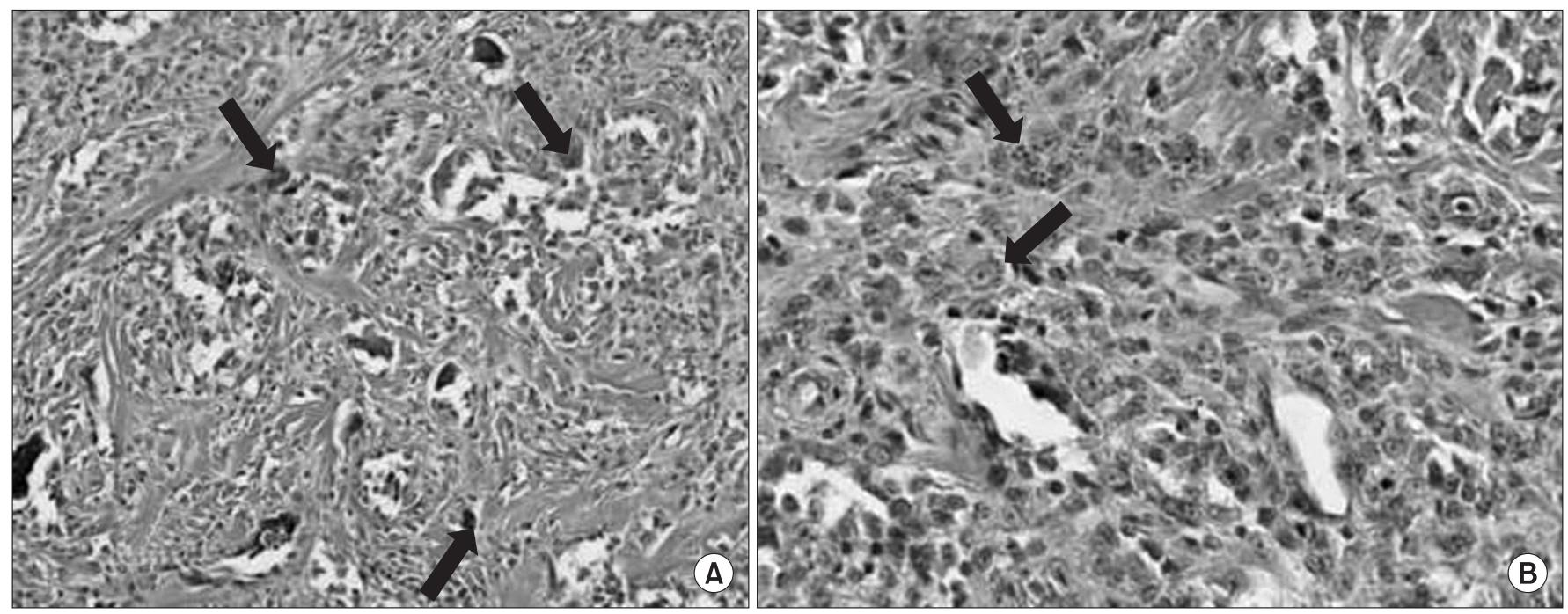

Fig. 4. (A) Histopathology (H\&E, $\times 100)$ shows diffuse infiltration of mononucleated round cells admixed with multinucleated giant cells (arrows) in a collagen stroma. (B) Histopathology (H\&E, $\times 250)$ shows xanthoma cells with hemosiderin (siderophages) pigments (arrows).

On arthroscopic examination, a yellowish oval shaped mass of pedunculated type protruding through the patellofemoral joint was found. No abnormal findings of hypertrophy of the medial plicae were found and the articular cartilage of the patella and femur was not injured. We made a high anterolateral portal as a viewing portal. En bloc resection of the mass was done through the anteromedial working portal (Fig. 2). The size of the resected mass was $14 \times 10 \times 11 \mathrm{~mm}$ and it was a yellowish solid tissue with clear margin, and the color inside was dark-brown (Fig. 3).

In hematoxylin and eosin stain, pathologic studies showed histiocyte, fibrous tissue, and giant cells. Multinucleated giant cells mixed in a collagen stroma and macrophage that has eaten hemosiderin were found. It was diagnosed as localized nodular tenosynovitis originating from synovium just above the medial plicae (Fig. 4). Pain and mechanical symptoms were relieved immediately after surgery. During the 1-year follow-up, no recurrence of preoperative symptoms or abnormalities was found in physical examination.

\section{Discussion}

Localized nodular tenosynovitis occurs typically in the hand and rarely in the ankle, foot and knee ${ }^{1-3}$. It is usually found as a nodular or polypoid mass in the intra-articular or extra-articular space $^{7}$. The etiology includes benign tumor theory, theory of hyperproliferation due to trauma, infection, disorder in the immune system, vascular abnormality, lipid metabolism disorder, etc.

The Symptoms and clinical features mimic those of meniscal lesions, such as locking and joint effusion. Sometimes a mass-like lesion is palpated in the joint line ${ }^{8)}$.

In our case, the mass was palpated under the skin and pain aggravated when the knee was flexed and relieved when extended, which was attributed to increased compression force on the mass between the bony architectures, such as the knee and femur and soft tissue, such as medial retinaculum. Meanwhile, when the mass was not palpable, the degree of aggravation or pain relief was insignificant, and this was considered attributable to the difference of compressive force and mechanical irritation to the adjacent structures.

The localized giant cell tumor showed similar to decreased signal intensity compared to the smooth muscle near the joint on the $\mathrm{T} 1$ images of the magnetic resonance, and similar signal intensity on the $\mathrm{T} 2$ images of the magnetic resonance. These findings are similar to those of diffuse type (pigmented villonodular synovitis), which makes it difficult to distinguish using MRI alone ${ }^{4,5)}$. Angioma, synovial chondroma, synovial sarcoma, medial plicae syndrome should also be distinguished. However, it is difficult to distinguish these diseases only with physical and radiological examinations, so histological examination is necessary for confirmation ${ }^{9}$.

Histological examination reveals hypertrophy of the tendon or synovium with subintimal macrophage infiltration. There are many macrophages and scattered multinucleated giant cells ${ }^{10)}$.

Treatment option for a localized giant cell tumor of the tendon sheath is surgical resection. Arthroscopic resection is recommended for a solitary lesion of a large joint. Open excision is useful for an extra-articular lesion and an inaccessible intra-articular 
lesion $^{10)}$.

Here, the authors report a rare case of a localized giant cell tumor of the tendon sheath in the medial plicae of the knee that was palpable on the skin and elicited significant pain and aggravating locking phenomenon in knee flexion and relief in extension with a review of the literature.

\section{Conflict of Interest}

No potential conflict of interest relevant to this article was reported.

\section{References}

1. Weiss SW, Goldblum JR. Benign tumors and tumor like lesions of synovial tissue. In: Enzinger FM, Weiss SW, eds. Soft tissue tumors. 3rd ed. St Louis: Mosby; 1995. p412-41.

2. Rosenberg AE. Soft tissue tumors and tumor-like lesions. In: Cotran RS, Kumar V, Robbins SL, eds. Robbins pathologic basis of disease. 5th ed. Philadelphia: Saunders; 1994. p12601.

3. Lee KH, Park MR, Lee JM, Seo KW. Giant cell tumor of tendon sheath in the digit. J Korean Soc Surg Hand. 1999;4:25863.

4. Jelinek JS, Kransdorf MJ, Shmookler BM, Aboulafia AA,
Malawer MM. Giant cell tumor of the tendon sheath: MR findings in nine cases. AJR Am J Roentgenol. 1994;162:91922.

5. Koo BS, Kim KC, Lee HJ. Localized giant cell tumor of tendon sheath arising from the anterior cruciate ligament of the knee: 2 case report. J Korean Arthroscopy Soc. 1999;3:146-9.

6. Kim SJ, Choi NH, Lee SC. Tenosynovial giant-cell tumor in the knee joint. Arthroscopy. 1995;11:213-5.

7. van der Heijden L, Gibbons CL, Dijkstra PD, Kroep JR, van Rijswijk CS, Nout RA, Bradley KM, Athanasou NA, Hogendoorn PC, van de Sande MA. The management of diffusetype giant cell tumour (pigmented villonodular synovitis) and giant cell tumour of tendon sheath (nodular tenosynovitis). J Bone Joint Surg Br. 2012;94:882-8.

8. Nau T, Chiari C, Seitz H, Weixler G, Krenn M. Giant-cell tumor of the synovial membrane: localized nodular synovitis in the knee joint. Arthroscopy. 2000;16:E22.

9. Chung WY, Kim YC, Jo SK. Localized form of tenosynovial giant cell tumor arising from the posterior cruciate ligament of the knee: 2 case report. J Korean Arthroscopy Soc. 2003;7:87-91.

10. De Ponti A, Sansone V, Malchere M. Result of arthroscopic treatment of pigmented villonodular synovitis of the knee. Arthroscopy. 2003;19:602-7. 